\title{
Extensive Mongolian spots: a clinical sign merits special attention for gm1-Gangliosidosis
}

\author{
Kumar $\mathbf{R}^{1}$ Gupta $A^{2}$, Mathur $P^{3}$, Sharma $M^{4}$, Garg $M^{5}$ \\ ${ }^{1}$ Dr Rajesh kumar, Senior Resident, Department of Paediatrics, ${ }^{2}$ Dr Ashok Gupta, Professor and Unit Head, Department \\ of Paediatrics, ${ }^{3}$ Dr Priyanshu Mathur, Assistant Professor, Department of Paediatrics, ${ }^{4}$ Dr Manish Sharma, Consultant \\ Pediatrician and In-charge, Accident Emergency, Department of Paediatrics, ${ }^{5}$ Dr Manisha Garg, Senior Resident, \\ Department of Paediatrics. All are affiliated with SMS Medical College, Jaipur, Rajasthan, India.
}

Address for Correspondence: Dr. Rajesh kumar, Senior Resident, SMS Medical College, Jaipur, Rajasthan, India. Email: rajesh.kumar.amc1985@gmail.com

\begin{abstract}
GM1-gangliosidosis (GM1) is one of the metabolic storage diseases, of which a differential diagnosis requires an array of biochemical assays to determine the enzyme deficiency. This approach is not only time-consuming and costly but also unavailable to most hospital laboratories. However, a presumptive diagnosis of GM1 may be made on the basis of diffuse ecchymosis, ectopic Mongolian spots and coarse facial feature, if present. A more definitive diagnosis of GM1 is then made on the demonstration of deficiency of GM1 beta-galactosidase in leukocytes, plasma or cultured skin fibroblasts. We postulate that dermal pigmentation may be recognized as an early sign of GM1 gangliosidosis.
\end{abstract}

Keywords: GM1 gangliosidosis, Ecchymoses, Mongolian spots

\section{Introduction}

GM1 gangliosidosis is an autosomal recessive lysosomal storage disorder with an estimated incidence of between 1 in 100,000 and 1 in 200,000 [1]. Clinical features are predominantly those of a neurodegenerative disorder due to GM1 ganglioside deposition in the central nervous system (CNS). Other clinical features include hepatosplenomegaly, coarse facial features, variety of cutaneous signs and skeletal dysostosis. The underlying biochemical abnormality is a deficiency of $\beta$-galactosidase whose level of activity is inversely proportional to disease severity [2].

While the disease is relatively heterogeneous three clinical subtypes are recognized. In the severe infantile form enzyme activity may be $0.07-1.3 \%$ of normal and clinical signs emerge between birth and 6 months of age. The clinical signs are a combination of a neurolipidosis (i.e., neurodegeneration and macular cherry-red spots) and a mucopolysaccharidosis (i.e., organomegaly, dysostosis and coarse facial features). The infantile form is characterised by a rapidly

Manuscript received: $4^{\text {th }}$ June 2016

Reviewed: $13^{\text {th }}$ June 2016

Author Corrected; $24^{\text {th }}$ June 2016

Accepted for Publication: $9^{\text {th }}$ July 2016 progressive course with severe CNS degeneration and death by 1-2 years of age commonly due to aspiration pneumonia or cardiomyopathy [2].

The juvenile form is associated with enzyme activity in the order of $0.3-4.8 \%$ of normal and presents between 7 months and 3 years of age. It is characterised by psychomotor retardation with the other features of the infantile form being present in variable degrees. Disease progression is slower than the infantile form and death typically occurs before the second decade of life. The adult form occurs in those with an enzyme activity in the region of $5-10 \%$ of normal and is characterised by normal early neurological development with symptom onset between 3-30 years of age. Characteristic features are of a slowly progressive dementia, parkinsonism and dystonia. There is marked phenotypic variability in the adult form and the age of death varies widely. The diagnosis can be made by measuring $\beta$-galactosidase activity in peripheral blood leucocytes or by $\beta$ galactosidase gene $(G L B 1)$ molecular testing. Over 100 mutations have been reported in GLB1 and there is no clear correlation between genotype and phenotype [1]. 
There are currently no effective therapies for GM1 gangliosidosis and only supportive treatments can be offered. Bone marrow transplantation for one patient with infantile GM1-gangliosidosis has been performed and this normalised leucocyte $\beta$-galactosidase levels but failed to impact on neurological deterioration [3]. Laboratory studies have reported attempts to reduce the substrate for ganglioside formation using imino sugars which are competitive inhibitors of the ceramide specific glucosyltransferase that catalyses the first step in glycosphingolipid biosynthesis. This successfully inhibited ganglioside biosynthesis in rodents and reduced the accumulation of gangliosides in the CNS $[4,5]$. This strategy, however, has no effect to increase $\beta$-galactosidase activity. Another proposal is to use a chemical chaperone, N-octyl-4-epi- $\beta$-valienamine (NOEV), to stabilise the mutant $\beta$-galactosidase. A study has demonstrated in a GM1 gangliosidosis mouse model treated with NOEV a marked increase in enzyme activity and a reduction in CNS storage of GM1 ganglioside with prevention of neurological deterioration $[6,7]$. However, this therapy is dependent on subjects having residual $\beta$-galactosidase activity.

\section{Case Report}

A 9-month-old boy was born to non-consanguineous Indian parents at term by normal vaginal delivery with birth weight of $2.6 \mathrm{~kg}$. At age of 2 months, he developed macula-papular rashes first over abdomen then spread to trunk and back. He was unable to sit, roll over, crawl, laugh or smile on social contact. He also had growth delay: weight $6.8 \mathrm{~kg}$ (between $2 \mathrm{SD}$ to $-3 \mathrm{SD})$ and occipitofrontal circumference $42 \mathrm{~cm}(<-2 \mathrm{SD})$. His examination revealed generalized hypotonia, gingival hypertrophy, coarse facial features, diffuse ecchymosis and numerous diffuse Mongolian spots on her trunk and back [Figures [Figures1-3]. Ophthalmologic exam showed bilateral macular cherry red spots and pale disc. Enzyme assay in leukocytes confirmed deficiency of acid beta-galactosidase.

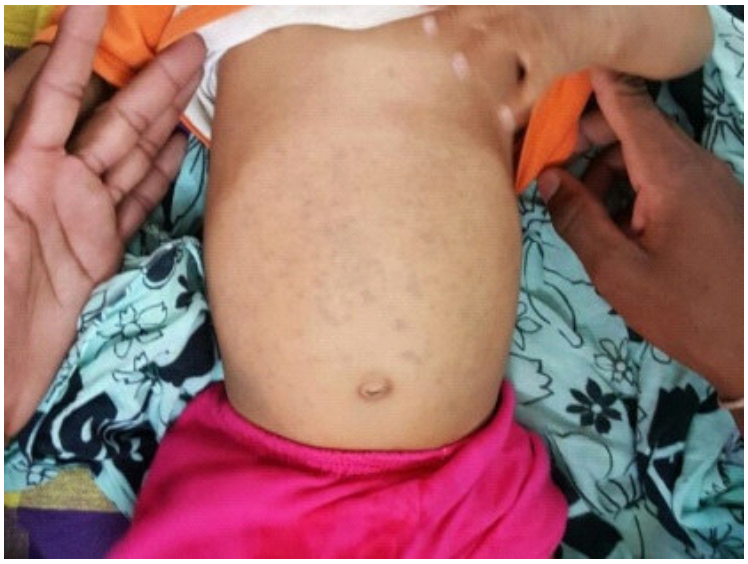

Figure-1: Numerous, diffuse ecchymoses and Mongolian spots on ventral surface of the trunk

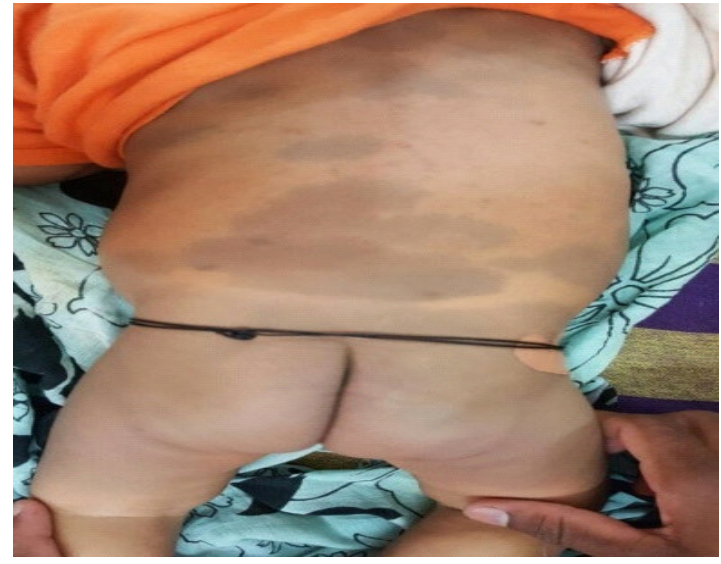

Figure- 2: Numerous, diffuse ecchymoses and Mongolian spots on dorsal surface of the trunk

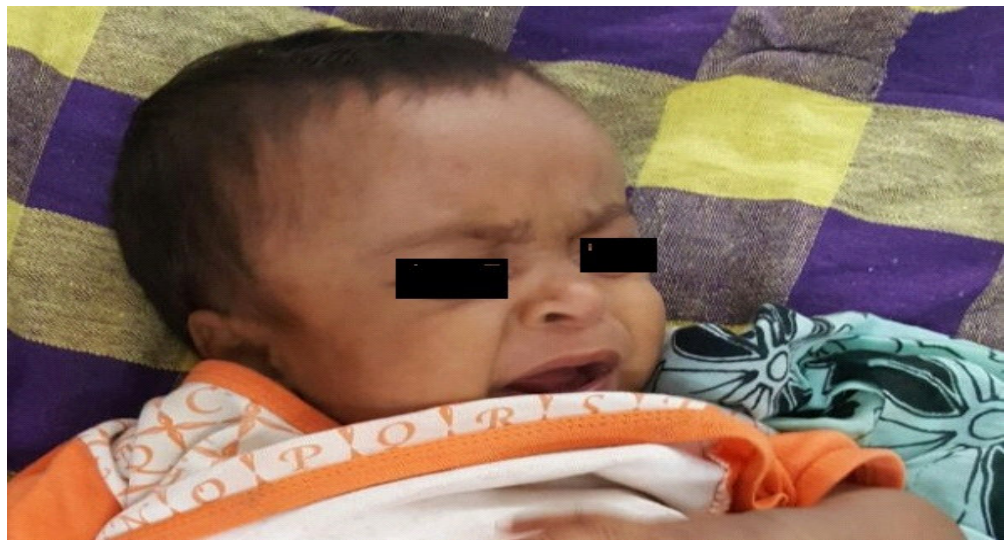

Figure -3: Coarse facial features 
The hyperpigmented skin lesions were apparent at birth and had not changed in number, position or size. The patient lacked any history of bleeding tendency and his platelet count, prothrombin time, partial thromboplastin time, bleeding time and fibrinogen level were all normal. His liver function test and renal function test were normal. His Cranial sonography revealed altered echotexture of brain parenchyma. His electroencephalogram revealed irregular slow activity with occasional bursts and spikes of slow waves in a depressed background. The activity of GM1 beta-galactosidase in leukocytes was analyzed and reported marked deficiency $(0.08 \%)$.

\section{Discussion}

Clinical and biochemical evidence supported the diagnosis of GM1 gangliosidosis type 1 in our patient. He had numerous and diffusely distributed hyperpigmented lesions which is an unusual presentation for typical Mongolian spots. He also had diffuse ecchymosis without an obvious cause.

Dermatologic findings are not commonly described in GM1 gangliosidosis. Eczematoid facial rash, truncal macular rash, angiokeratomas and generalized telangiectasia, in patients with this illness, have been sporadically described in the literature. $[8,9,10,11]$ However, diffuse, extensive and unusual Mongolian spots have been reported in increasing number of cases of GM1 gangliosidosis type 1 in recent years. [12-13].

Table- 1: Cutaneous findings reported in children with GM1 gangliosidosis.

\begin{tabular}{|c|c|c|c|c|c|}
\hline Source & Year & Gender & Ethnicity & Age* & Lesion \\
\hline Landing et al [8] & 1964 & NA & NA & NA & Rash \\
\hline Hooft et al [9] & 1969 & NA & NA & NA & Telangiectasia \\
\hline Ginsburg et al [10] & 1977 & NA & NA & NA & Telangiectasia \\
\hline Beratis et al [11] & 1989 & $\mathrm{M}$ & Greek & 3 & Mongolian spot and angiokeratomas \\
\hline Weissbluth et al [12] & 1981 & $\mathrm{~F}$ & AA & 5 & Mongolian spot \\
\hline Selsor et al [13] & 1989 & $\mathrm{M}$ & AA & 10 & Mongolian spot \\
\hline Beattie et al [14] & 1992 & $\mathrm{~F}$ & Pakistani & 5 & Mongolian spot \\
\hline Tang et al [15] & 1993 & $\mathrm{~F}$ & AA & 13 & Mongolian spot \\
\hline Silengo et al [16] & 1999 & $\mathrm{~F}$ & Caucasian & 2 & Mongolian spot \\
\hline Ashrafi et al [17] & 2006 & M & Iranian & 12 & Mongolian spot \\
\hline Hanson et al [18] & 2003 & $\mathrm{M}$ & NA & NA & Mongolian spot \\
\hline Present report & 2016 & M & Indian & 9 & Mongolian spot and ecchymosis \\
\hline
\end{tabular}

$\mathrm{NA}=$ not available; $\mathrm{M}=$ male; $\mathrm{F}=$ female; $\mathrm{AA}=\mathrm{A}$ frican American; *Age in months;

Table 1 summarizes the reported cutaneous findings in these patients. This association has also been described with other lysosomal storage diseases such as Hurler's and Hunter's syndromes. [18, 19]

\section{Conclusions}

Although a chance association of the dermal findings and GM1 gangliosidosis cannot be excluded, we think our patient adds to the increasingly recognized evidence that patients with this disorder may manifest abnormal dermal pigmentary lesions, which may be present at birth thus helping physicians make an earlier diagnosis. Whether the ecchymosis in our patient is incidental or part of the dermal endothelial vasculopathy associated with GM1 gangliosidosis and other lysosomal storage diseases needs to be investigated further. We are not aware of this association in the literature and its significance in the diagnosis is not yet clear.

Funding: Nil, Conflict of interest: Nil Permission from IRB: Yes 
Case Report

\section{References}

1. Brunetti-Pierri N, Scaglia F. GM1 gangliosidosis: review of clinical, molecular and therapeutic aspects. Mol Genet Metab. 2008 Aug; 94(4):391-396.

2. Carl Hayward, Hitesh C. Patel, Sanjay G. Manohar, Alexander R. Lyon. Gene therapy for GM1 gangliosidosis: challenges of translational medicine. Ann Transl Med. 2015 May; 3(Suppl 1): S28.

3. Shield JP, Stone J, Steward CG. Bone marrow transplantation correcting beta-galactosidase activity does not influence neurological outcome in juvenile GM1-gangliosidosis. J Inherit Metab Dis. 2005; 28(5) : 797-8.

4. Kasperzyk JL, El-Abbadi MM, Hauser EC, et al. Nbutyldeoxygalactonojirimycin reduces neonatal brain ganglioside content in a mouse model of GM1 gangliosidosis. J Neurochem. 2004 May; 89 (3):645-53.

5. Kasperzyk JL, d'Azzo A, Platt FM, et al. Substrate reduction reduces gangliosides in postnatal cerebrumbrainstem and cerebellum in GM1 gangliosidosis mice. J Lipid Res.2005Apr;46(4):744-51.

6. Matsuda J, Suzuki O, Oshima A, et al. Chemical chaperone therapy for brain pathology in GM1gangliosidosis. Proc Natl Acad Sci U S A. 2003 Dec;100(26):15912-7.

7. Suzuki Y, Ichinomiya S, Kurosawa M, et al. Chemical chaperone therapy: clinical effect in murine GM1- gangliosidosis.Ann Neurol.2007Dec;62(6):671-5.

8. Landing BH, Silverman FN, Craig GM, Jacoby MD, Lahey ME, Chadwick DL. Familial neurovisceral lipidosis. Am J Dis Child. 1964 Nov;108:503-22.

9. Hooft C, Senesael L, Delbeke MJ, Kint J, Dacremont

G. The Gm1 gangliosidosis (Landing disease). Eur Neurol.1969; 2(4):225-41.

10. Ginsburg CM, Long CG. GM1 gangliosidosis type 1 in twins. J Med Genet. 1977 Apr;14(2):132-4.
11. Beratis N, Varvarigou-Frimas A, Beratis S, Sklower S.Angiokeratoma corporis diffusum in GM1 gangliosidosis, type1. Clin Genet.1989 Jul; 36 (1): 59-64.

12. Weissbluth M, Esterly NB, Caro WA. Report of an infant with GM1 gangliosidosis type I and extensive and unusual mongolian spots. $\mathrm{Br} J$ Dermatol. 1981 Feb;104(2):195-200

13. Selsor LC, Lesher JL., Jr Hyperpigmented macules and patches in a patient with GM1 type 1 gangliosidosis. J Am Acad Dermatol. 1989 May; 20 (5 Pt 2): 878-82

14. Beattie RM, Harvey D. Extensive and unusual Mongolian blue spots in a child with $\mathrm{GM}_{1}$ gangliosidosis type one. $J R$ Soc Med. 1992 Sep; 85(9):574-5

15. Tang TT, Esterly NB, Lubinsky MS, Oechler HW, Harb JM, Franciosi RA. GM1-gangliosidosis type 1 involving the cutaneous vascular endothelial cells in a black infant with multiple ectopic mongolian spots. Acta Derm Venereol. 1993 Dec; 73(6):412-5.

16. Silengo M, Battistoni G, Spada M. Is there a relationship between extensive Mongolian spots and inborn error of metabolism? Am J Med genet. 1999 Nov; 87(3):276-7.

17. Ashrafi MR, Shabanian R, Mohammadi M, Kavusi S. Extensive Mongolian spots: a clinical sign merits special attention. Pediatr Neurol.2006Feb;34(2):143-5.

18. Hanson M, Lupski JR, Hicks J, Metry D. Association of dermal melanocytosis with Lysosomal storage disease. Arch Dermatol. 2003 July; 139(7):91620.

19. Ochiai T, Ito K, Okada T, Chin M, Shichino H, Mugishima H. Significance of extensive Mongolian spots in Hunter's syndrome. Br J Dermatol. 2003 June; 148(6):1173-8.

\section{How to cite this article?}

Kumar R Gupta A, Mathur P, Sharma M, Garg M. Extensive Mongolian spots: a clinical sign merits special attention for gm1-Gangliosidosis. Int J Pediatr Res.2016;3(7):482-485.doi:10.17511/ijpr.2016.i07.03. 